\title{
REVERSIBLE HYPERTENSIVE BRAINSTEM ENCEPHALOPATHY COEXISTENT WITH ACUTE INTRACEREBRAL HEMORRHAGE
}

\author{
Mehmet Akif TOPÇUOGLU*, Esma BİNOL**, Ethem Murat ARSAVA*, Kader KARLI OĞUZ***, Ali \\ ÜNAL ${ }^{* * * *}$, Sevda DIKER ${ }^{* * * * *}$, Lale MEHDIKHANOVA******, Erhan AKPINAR ${ }^{* * *}$, Rahşan GöÇMEN ${ }^{* * *}$ \\ *Hacettepe University Hospitals, Department of Neurology, Ankara, TURKEY \\ **Batman Regional State Hospital, Neurology Clinic, Batman, TURKEY \\ ***Hacettepe University Hospitals, Department of Radiology, Ankara, TURKEY \\ ****Akdeniz University Hospitals, Department of Neurology, Antalya, TURKEY \\ *****Near-East University Hospitals, Department of Neurology, Lefkoşa, CYPRUS \\ ******Private Sevgi Hospital, Neurology Clinic, Balıkesir, TURKEY
}

\begin{abstract}
We report two cases of reversible hypertensive brainstem encephalopathy (RHBE) syndrome with other concurrent manifestations of malignant hypertension. RHBE was accompanied by hypertensive putaminal hemorrhage in one case, and by intra-ventricular hemorrhage resulting acute obstructive hydrocephalus along with multiple small acute infarctions in the other. Diffusion-weighted imaging and corresponding apparent diffusion coefficient mapping disclosed increased diffusion suggestive of vasogenic edema centered in the pons. No lesion indicative for posterior reversible encephalopathy syndrome (PRES) was noted in the supratentorial regions. These cases indicate that mechanisms involved in development of RHBE and hypertensive PRES may have some differences, albeit both share main lines. These cases also underline that awareness and knowledge about relatively specific clinic-radiological syndrome caused by RHBE seem to be critical. Acute treatment and early prognostification are just only accurate with such a familiarity.
\end{abstract}

Key Words: Posterior leukoencephalopathy syndrome, central pontine myelinolizis, stroke, pons.

\section{IZOLE GERİ DÖNÜŞÜMLÜ HIPPERTANSIF BEYINSAPI ENSEFALOPATİSİ VE İNTRASEREBRAL KANAMA}

\section{ÖZET}

$\mathrm{Bu}$ makalede malign hipertansiyonun diğer bulguları ile eş zamanlı gelişen Reversible Hipertansif Beyin Sapı Ensefalopati (RHBE) sendromu olan iki olgu bağlamında sürecin fizyopatolojisi tartışılmaktadır. Sunulan olgulardan birinde RHBE'ye "hipertansif putaminal hemoraji", diğerinde ise "akut obstrüktif hidrosefaliye yol açan intraventriküler kanama" eşlik etmektedir. RHBE'de lezyon difüzyon ağırlıklı görüntüleme/ADC ("apparent diffusion coefficient") haritalamalarına göre vazojenik ödemdir. Vakalarda supratentorial alanda posterior reversibl ensefalopati sendromunun (PRES) herhangi bir bulgusu görülmemektedir. Dolayısıyla, bu olgular temelinde RHBE ve hipertansif PRES gelişiminde rol oynayan mekanizmaların, ana süreç kapsamında benzeşim olsa da bazı kritik farklılıkları içerebileceğini işaret etmektedir. Diğer taraftan, bu vesile ile RHBE'nin neden olduğu nispeten spesifik klinik-radyolojik sendrom hakkındaki farkındalığı da artırmış oluyoruz. Bu aşinalık akut dönem tanı, tedavi ve prognoztifikasyonda kritik önemde olabilir.

Anahtar Sözcükler: Posterior leukoencephalopathy syndrome, PRES, sentral pontin myelinolizis, CPM, inme, pons.

\footnotetext{
Corresponding author: Prof. Mehmet Akif Topçuoğlu MD. Hacettepe University Faculty of Medicine, Department of Neurology, Ankara, Turkey. Phone: +90 03123051809 E-mail: mat@hacettepe.edu.tr Received: $14.06 .2018 \quad$ Accepted: 23.07 .2018

This article should be cited as following: Topçuoğlu M. A, Binol E, Arsava E.M, Karlı Oğuz K, Ünal A, Diker S, Mehdikhanova L, Akpınar E, Göçmen R. Reversible hypertensive brainstem encephalopathy coexistent with acute intracerebral hemorrhage. Turkish Journal of Cerebrovascular Diseases 2019 ; 25 (1): 42-47. doi:10.5505/tbdhd.2018.36449
} 


\section{INTRODUCTION}

\begin{abstract}
Posterior reversible encephalopathy syndrome (PRES) predominantly occurs due to malignant hypertension in immune competent persons. The usual lesion pattern characterizing PRES is white matter vasogenic edema primarily affecting the posterior occipital and parietal lobes of the brain (1). However, atypical forms and variants are not rare (2). Reversible hypertensive brainstem encephalopathy (RHBE) is one of the well-described but widely under-recognized PRES variants $(3,4)$. When concomitant typical parietooccipital lesions are absent, this unusual pattern is difficult to diagnose. RHBE may not necessarily present with symptoms attributable to brainstem dysfunction and therefore its diagnosis is more challenging especially in an emergency setting. Differential diagnosis of RHBE is wide, and includes brainstem infarction, central pontine myelinolysis, and perhaps brain stem tumor or infection (5-7). Prompt recognition of RHBE and adequate control of increased blood pressure offer the best outcomes (8). However, if knowledge and awareness about this entity are not readily available, time lost during working through the list of differential diagnoses, or prioritizing other diagnoses such as brainstem ischemia, in which aggressive blood pressure reduction is not generally suggested, may negatively affect the prognosis. We believe that familiarity of the (non-)neurologist physicians including emergency doctors to RHBE is still low despite more than fifty RHBE cases reported in the pertaining literature. This thought has motivated us to revisit this entity using these two cases, and discuss them from an emergency neurology perspective.
\end{abstract}

CASE I. A 42-year-old man presented with suddenonset headache, nausea, confusion, global aphasia and right-hemiparesis. His past medical history was unremarkable except for arterial hypertension under medication for 4 years. Blood pressure was $260 / 120 \mathrm{mmHg}$ at admission. Emergency brain computerized tomography (CT) disclosed a leftsided putaminal hemorrhage (Figure I a). Brain magnetic resonance (MR) imaging obtained 5 hours later than CT showed a diffuse lesion, centered in the pons and characterized with T2-hyperintensity and increased diffusion (Figure I b, c and d) in addition to putaminal hematoma (Figure I e). There was no contrast enhancement. He improved dramatically following meticulous hypertension control. Complete resolution of brainstem abnormalities was observed on brain MR imaging obtained on the $22^{\text {nd }}$ day after symptom onset (Figure I f, g and h). He was discharged with slight right sided hemiparesis which completely resolved in the following three months.

CASE II. A 46-year-old male with Behcet's disease, diagnosed 20 years ago, presented with headache, nausea, vomiting along with uncooperativeness and sleepiness that progressively worsened over 4 days. At admission, he was stuporous (Glasgow coma scale: 8). Neck stiffness was notable. Blood pressure was 180/130 mmHg. Medical history revealed that he was on warfarin for recurrent leg thrombophebilitis for the last 2 years in addition to regular use of colchicine and alpha interferon for Behcet's disease. An emergency brain CT showed a hemorrhage in the third ventricle causing acute obstructive hydrocephalus (Figure II a). Blood tests showed normal results except for a slight elevation of liver transaminases (alanine aminotransferase (ALT): $119 \mathrm{U} / \mathrm{L} \quad($ normal<41) and aspartate aminotransferase (AST): $65 \mathrm{U} / \mathrm{L}$, normal<37), and international normalized ratio (INR: 1.50). After receiving fresh frozen plasma and vitamin $\mathrm{K}$, he was transferred to neurological intensive care unit. A brain MR imaging, obtained seven hours after admission CT, disclosed similar volume intraventricular hemorrhage and hydrocephalus. A trace hemorrhage in the right occipital horn of the lateral ventricle was discernible (Figure II b, c, d). Two dot-like lesions characterized with diffusion restriction were also noted in the right anterior cerebral artery territory (Figure II e). The most striking finding in this MRI was a lesion characterized with increased diffusion (DWI and ADC bright) encompassing almost the entire pons with some extension to the midbrain, which was typical for RHBE. Of note, there was no accompanying posterior dominant cortical and subcortical edema characteristic for PRES (Figure II $\mathrm{f}, \mathrm{g}$ and $\mathrm{h}$ ). There was also no contrast enhancement (Figure II i and j). On the next day, his mental status started to recover gradually after successful blood pressure control and hemostasis correction. A repeat MR imaging 7 days later revealed complete resolution of hydrocephalus and RHBE (Figure III). He was discharged without neurological deficit at the end of the second week. 

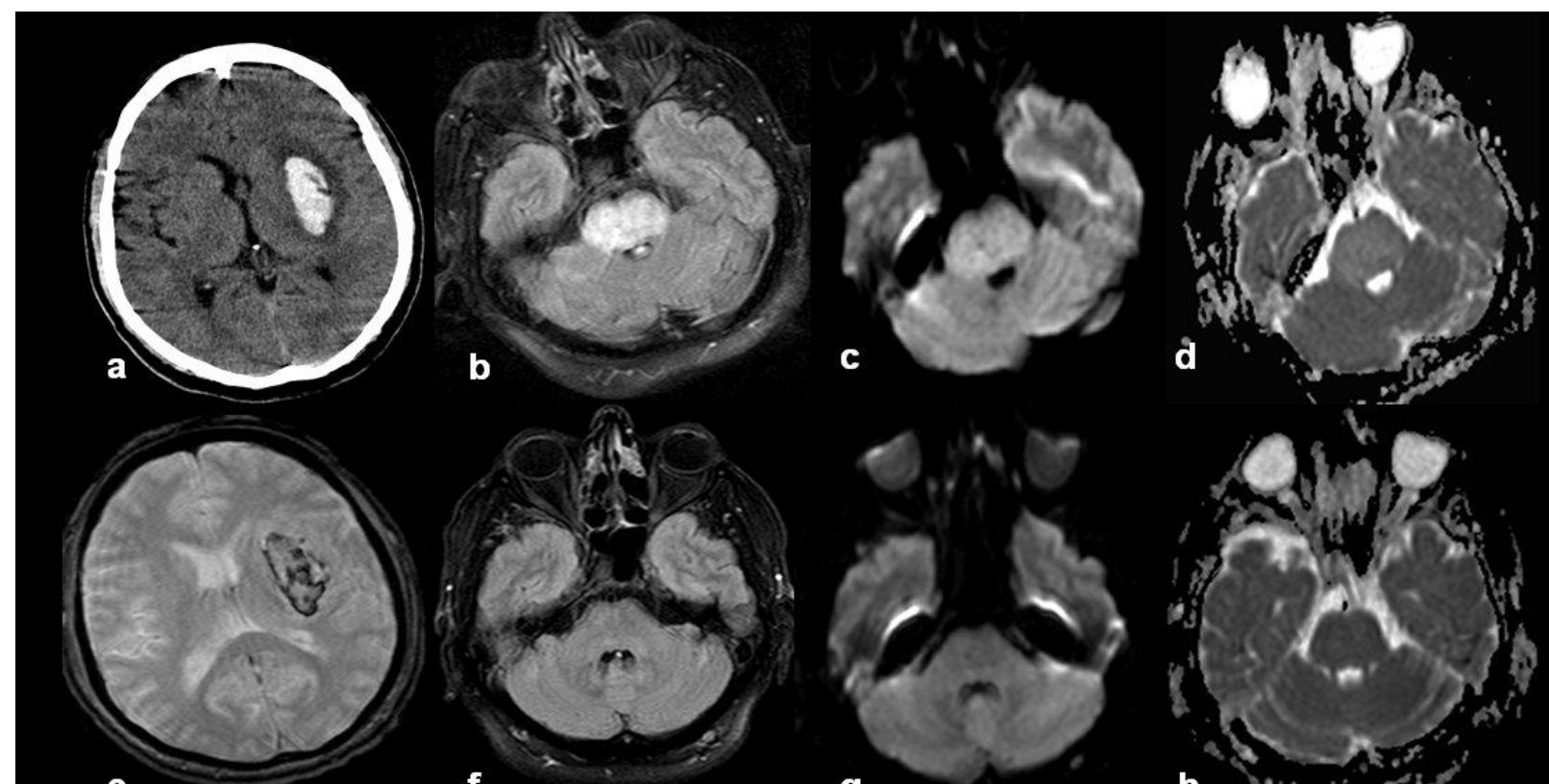

b
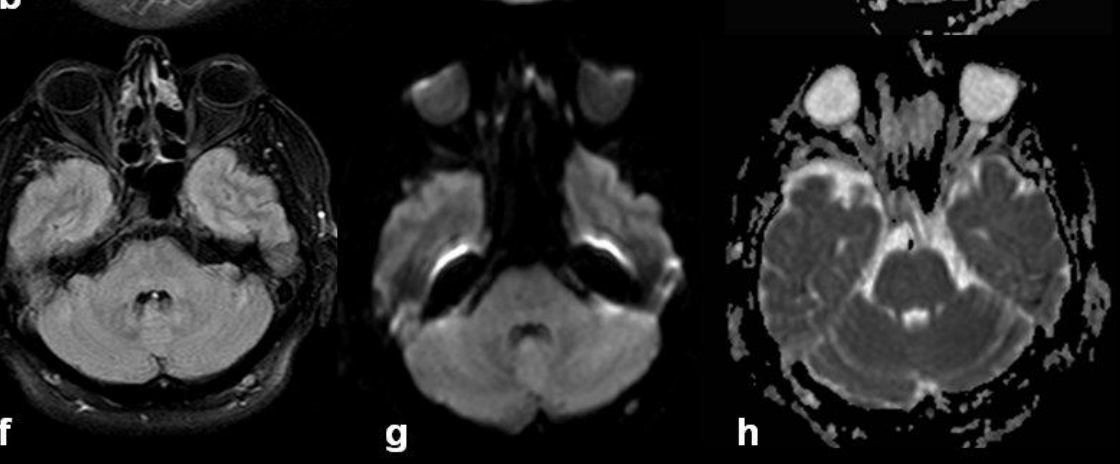

Figure I a. Axial computed tomography (CT) of the brain shows a hypertensive putaminal hemorrhage on the left; b. Fluid attenuated inversion recovery (FLAIR) MR imaging shows diffuse hyperintensities through the pons; $\mathbf{c}$, $\mathbf{d}$. This lesion is compatible with vasogenic edema, which is bright on both diffusion-weighted imaging and corresponding apparent diffusion coefficient (ADC) maps. ADC was measured as $1.25 \times 10-3 \mathrm{~mm} 2 / \mathrm{sec}$; e. There are no old microhemorrhages in addition to putaminal hemorrhage on gradient (T2*) MR imaging; f, $\mathbf{h}$. A complete disappearance of brainstem lesion in FLAIR, diffusion-weighted and ADC images is noted on follow-up. ADC was measured as $0,94 \times 10 \times 10-3 \mathrm{~mm} 2 / \mathrm{sec}$.

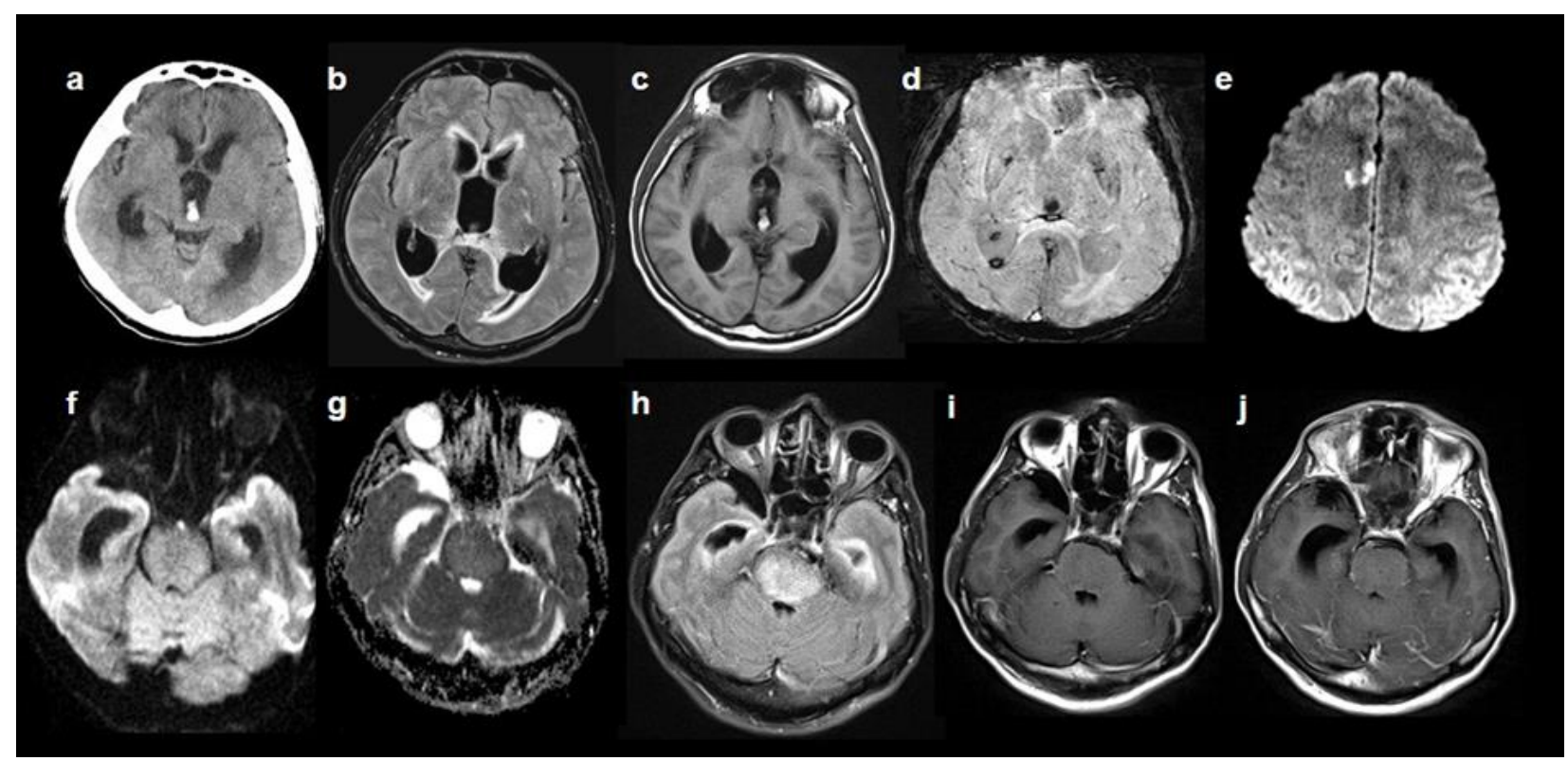

Figure II a. Axial head CT discloses obstructive hydrocephalus with hemorrhage located in the aqueduct; b, c. T2-and T1-weighted MR images show acute transependimal CSF leakage through the dilated ventricles; d. Susceptibility weighted imaging shows additional intraventricular blood seeding in the bottom of the lateral ventricles; e. Diffusion-weighted imaging shows small acute infarctions in the right anterior cerebral artery territory; f, g. Diffusion-weighted and ADC mapping disclose the FLAIR hyperintense; h. lesion encompassing the pons has increased diffusion consistent with vasogenic edema. ADC was measured as 1,05 x10-3 mm2/sec at presentation in the pontine lesion. The ADC decreased to $0,625 \times 10-3 \mathrm{~mm} 2 / \mathrm{sec}$ in follow-up study (images not provided) ; $\mathbf{i}-\mathbf{j}$. There is no contrast enhancement. 


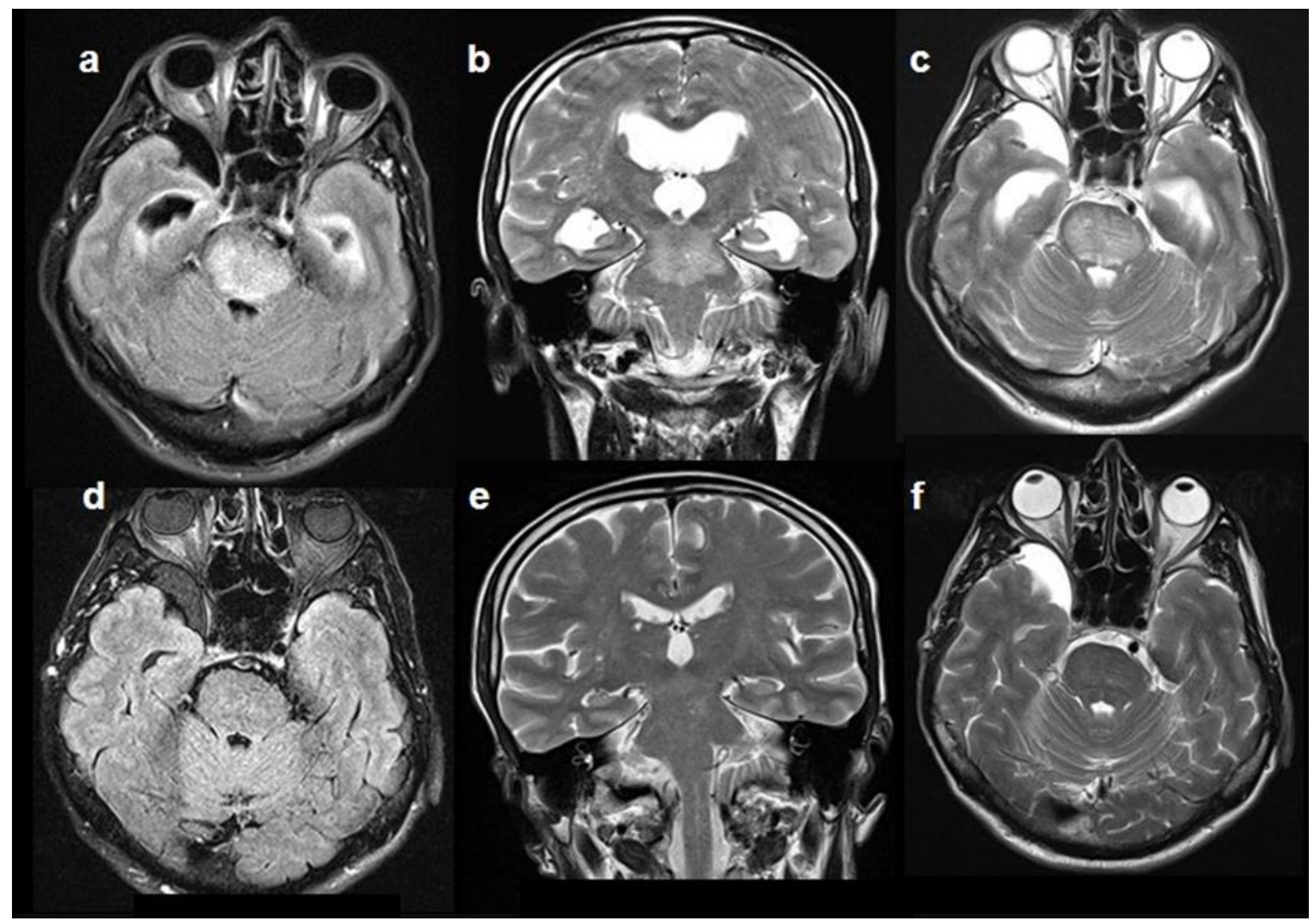

Figure III. Upper images (a: Axial FLAIR; b: Coronal T2-weighted and c: Axial T2-weighted): Obstructive hydrocephalus and brainstem encephalopathy. Lower images (d: Axial FLAIR; e: Coronal T2-weighted and f: Axial T2-weighted): complete resolution of hydrocephalus, aqueductal hemorrhage and brainstem lesion.

\section{DISCUSSION}

The notable characteristics of these two RHBE cases presented in this report include presence of coexistent intracerebral hemorrhage and infarcts, but not the usual supra- and infratentorial PRES lesions following acute elevation of blood pressure to very high levels. This association is probably not rare; but has not been reported in the literature insomuch, and remains widely unrecognized. The vast majority of case reports of RHBE include isolated brainstem lesions without concomitant central nervous system manifestations of blood pressure elevation.

Rapid improvement of MR lesions is a key feature of RHBE. The other typical feature of RHBE is marked clinicoradiologic dissociation: mild neurologic symptoms against very significant and sometimes worrying pons dominant extensive brainstem lesion. However, in RHBE cases with additional cerebral lesion, like those presented in this report, determination of this dissociation may not be so simple. Albeit topographic and diffusion MR characteristics of RHBE and brain stem ischemia are different, it is not rare to perform acute diagnostic work-up for stroke. More importantly, stroke misdiagnosis may unduly give way to setting of blood pressure goals to higher levels, which may be deleterious for RHBE. RHBE has remarkably good prognosis with adequate and timely treatment, in turn, delay in diagnosis and treatment may lead to permanent neurological sequelae. Knowledge on this entity is not only crucial for correct treatment such as aforementioned acute antihypertensive medication, but also for accurate determination of prognosis. Prognostification is particularly complicated in this kind of patients with combined lesions. RHBE almost always occurs with accelerated hypertension. It is a specific subtype of 
hypertensive encephalopathy. In contrast, PRES can occur with many diverse clinical entities in addition to hypertension $(2,9,10)$. Nevertheless, RHBE and hypertensive subcategories of PRES may have similar pathophysiological mechanisms. Briefly, disordered cerebral autoregulation, usually due to vasospasm, is regularly implicated in hypertension-associated PRES pathophysiology. On the other hand, endothelial dysfunction is usually connected to PRES seen in cases without severe hypertension, such as cytotoxic therapies. Given the absence of any study comparing RHBE with cerebral/cerebellar typical PRES lesions, isolated RHBE and isolated PRES cases, the autoregulation breakthrough concept remains open to discussion. An explanatory model should also clearly formulate the anatomical preference of RHBE. Some speculate that the presence of fetaltype posterior cerebral arteries (PCAs) may spare the occipital lobe in RHBE. However, our experience was not affirmative for this idea because PCAs were not fetal type in both of our cases. Further, this hypothesis cannot explain why the cerebellum is not affected in RHBE albeit frequently involved in typical PRES (2).

Our RHBE cases had simultaneous intracerebral hemorrhage. The first case had typical hypertensive putaminal hematoma. In addition to being on anticoagulation, the second patient had also uncontrolled hypertension at the time of presentation. This case also had simultaneous relatively characteristic acute ischemic lesions recently described in patients who remained hypertensive after intracerebral hemorrhage (11). It is currently a mystery that why acute uncontrolled hypertension leads to a bleeding due to vascular rupture in one part of the cerebrum, while leading vasogenic edema probably due to vasospasm and/or impaired vascular permeability in another part and ischemia due to vessel obstruction in the other part. Despite these uncertainties, it is fortunate that clinical and radiological improvement is usually observed after prompt and strict blood pressure control (actually rapid normalization) in these cases. Furthermore, a spontaneous disappearance of an acute hydrocephalus caused by cerebral aqueduct obstruction by hematoma is notable in our case 2 and merits a brief discussion. To our knowledge, only two adult cases $(12,13)$ (in addition to several pediatric cases) $(14,15)$ with spontaneous resolution of hemorrhage related acute hydrocephalus without aspiration of cerebrospinal fluid has been published in the literature. The suggested mechanism is simple: resolution of the acute hemorrhage in the aqueduct results in resolution of the hydrocephalus itself.

In conclusion, RHBE exhibits a typical clinicoradiological syndrome, and should be recognized in a timely manner. Awareness of "the syndrome" is key to prevent unnecessary and potentially deleterious diagnostic tests or therapies.

\section{REFERENCES}

1. Hinchey J, Chaves C, Appignani B, et al. A reversible posterior leukoencephalopathy syndrome. The New England journal of medicine 1996; 334(8): 494-500.

2. Fugate JE, Claassen DO, Cloft HJ, Kallmes DF, Kozak OS, Rabinstein AA. Posterior reversible encephalopathy syndrome: associated clinical and radiologic findings. Mayo Clinic proceedings Mayo Clinic 2010; 85(5): 427-32.

3. Katsumata Y, Maehara T, Noda M, Shirouzu I, Shimokawa M, Hiyamuta E. Hypertensive encephalopathy: reversible CT and MR appearance. Radiation medicine 1993; 11(4): 160-163.

4. Weingarten K, Barbut D, Filippi C, Zimmerman RD. Acute hypertensive encephalopathy: findings on spin-echo and gradient-echo MR imaging. AJR American journal of roentgenology 1994; 162(3): 665-670.

5. Jurcic V, Ferluga D, Jeruc J, Pogacnik T, Popovic M. Hypertensive encephalopathy mimicking brainstem tumour in psychiatric patient. Folia neuropathologica / Association of Polish Neuropathologists and Medical Research Centre, Polish Academy of Sciences 2004; 42(1): 37-41.

6. Gamanagatti S, Subramanian S. Hypertensive encephalopathy: isolated pons involvement mimicking central pontine myelinolysis. Korean journal of radiology : official journal of the Korean Radiological Society 2006; $7(3):$ 218-219.

7. Uchino M, Haga D, Nomoto J, Mito T, Kuramitsu T. Brainstem involvement in hypertensive encephalopathy: a report of two cases and literature review. European neurology 2007; 57(4): 223-226.

8. Hsieh $\mathrm{CY}$, Chen $\mathrm{CH}$, Chang TP. Isolated brainstem involvement in a patient with hypertensive encephalopathy. Acta neurologica Taiwanica 2010; 19(1): 45-50.

9. Bas DF, Oguz KK, Topcuoglu MA. Atypical reversible posterior leukoencephalopathy syndrome in thrombotic thrombocytopenic purpura. Internal medicine 2008; 47(21): 1931-1934.

10. Gocmen R, Ozgen B, Oguz KK. Widening the spectrum of PRES: series from a tertiary care center. European journal of radiology 2007; 62(3): 454-459.

11. Arsava EM, Kayim-Yildiz O, Oguz KK, Akpinar E, Topcuoglu MA. Elevated admission blood pressure and acute ischemic lesions in spontaneous intracerebral hemorrhage. Journal of stroke and cerebrovascular diseases : the official journal of National Stroke Association 2013; 22(3): 250-254.

Turkish Journal of Cerebrovascular Diseases 2019; 25 (1): 42-47 
Topçuoğlu et al.

12. Nomura $S$, Orita $T$, Tsurutani $T$, Kajiwara $K$, Izumihara $A$. Transient hydrocephalus due to movement of a clot plugging the aqueduct. Comput Med Imaging Graph 1997; 21: 351-353.

13. Yaghi S, Hinduja A. Spontaneous resolution of obstructive hydrocephalus from blood in the cerebral aqueduct. Clinics and Practice 2011; 1(e15).
14. Inamura $T$, Kawamura $T$, Inoha $S$, Nakamizo A, Fukui $M$. Resolving obstructive hydrocephalus from AVM. Journal of clinical neuroscience : official journal of the Neurosurgical Society of Australasia 2001; 8(6): 569-570.

15. Abubacker M, Bosma JJ, Mallucci CL, May PL. Spontaneous resolution of acute obstructive hydrocephalus in the neonate. Child's nervous system : ChNS : official journal of the International Society for Pediatric Neurosurgery 2001; 17(3): 182-184. 